\title{
LA SARDANA A L'AULA: UNA EINA PER FUSIONAR DISCIPLINES; UNA DANSA PER UNIR CULTURES
}

\author{
Neus Saguer Canadell. Professora de mMúsica. IES Santiago Sobrequés. Girona \\ Montserrat Forcada Puig. Professora de Música. IES el Pedró. L’Escala \\ Elisabet Saguer Canadell i Pere Nogué Font. Professors de Matemàtiques. IES Jaume Vicens Vives. \\ Girona
}

Aquest darrer any ha sortit publicat el llibre UN TRES I FORA! Itineraris per aprendre a escoltar, comptar irepartir sardanes que correspon a una versió del treball que, sota el mateix títol, va estar guardonat amb el Premi Baldiri Reixac l'any 2000, que cada any atorga la Fundació Jaume I a escoles, mestres, professors i alumnes. Inicialment el treball va néixer d'una proposta del SEDEC amb la intenció de presentar activitats que contribuïssin a l'aprenentatge de la sardana des del punt de vista musical, lingüístic i social. Donada la complexitat d'aquesta dansa i la importància del repartiment en la

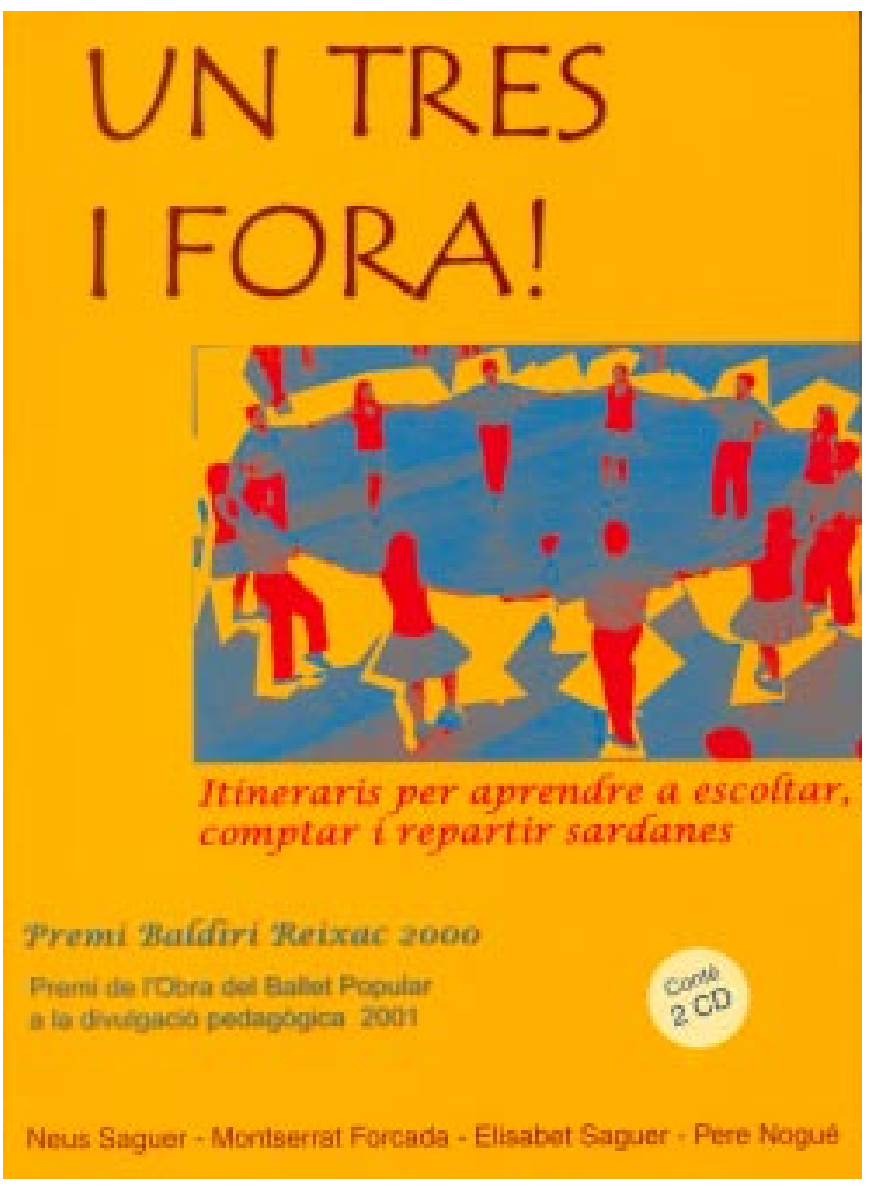

resolució de les tirades, es van ampliar els exercicis a l'àrea de matemàtiques amb el resultat final d'un material interdisciplinari.

El llibre es complementa amb un suport àudio de dos discos compactes per il.lustrar els diferents aspectes que conformen la sardana. Les audicions comprenen des de les sardanes més clàssiques $i$ carismàtiques fins a les composicions actuals, sense oblidar els treballs de fusió més recent. El primer conté 40 audicions de formes musicals d'estils diversos -des de ball rodó, cançons i música per a cobla- $i$ el segon disc, sis sardanes completes per ballar.

El contingut està distribuït en vuit amplis capítols que es poden treballar globalment sempre i quan l'alumnat tingui uns coneixements bàsics previs sobre música i sobre l'entorn sociocultural català. Tot i que els diferents capítols estan relacionats entre ells, són independents i, per tant, permeten un tractament autònom fàcilment adaptable a les necessitats i coneixements del grup. Caldrà que l'ensenyant valori quins capítols són els més adequats per a un aprenentatge eficient de la cobla, del ball de la sardana i de la seva història, de l'estructura de la dansa i del fet de comptar i repartir.

Els continguts i les activitats que es presenten són prou amplis $i$ variats perquè es puguin adaptar fàcilment com a tasques de diferents àrees: matemàtiques per aprendre a repartir; història i llengua per comprendre els orígens; plàstica per desenvolupar l'expressió gràfica i música per desxifrar un llenguatge artístic i la creativitat. $\mathrm{Si}$ es volen aplicar en diverses àrees els continguts que presentem, proposem dos itineraris que es poden ajustar fàcilment als diferents desplegaments curriculars:

Itinerari históric (àrees d'història, llengua, música i plàstica): capítols I (Les danses en rotllana), II (Els instruments de la cobla), III (L'ofici de músic de cobla), IV (L'estructura de la sardana), V (El ball de la sardana).

Itinerari per escoltar, comptar i repartir (àrees de matemàtiques i música): capítols II (Els instruments de la cobla), IV (L'estructura de la sardana), V (El ball de la sardana), VI (Repartiment a l'estil empordanès, VII (Altres maneres de repartir una sardana). 


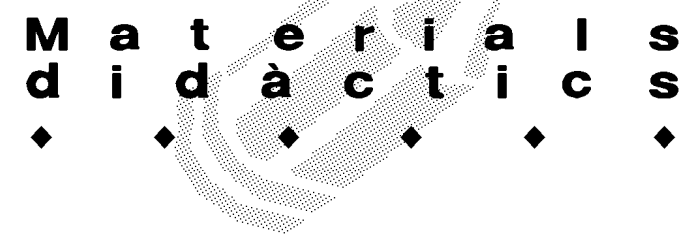

Les activitats proposades al llarg de vuit capítols tenen la solució al final del volum. Aquest fet, juntament amb la finalitat divulgativa i d'apropament a la dansa, fa que UN TRES / FORA:pugui ser utilitzat per un públic heterogeni: des de les aules d'ensenyament, a les escoles de música, fins als esbarts i a totes les persones interessades en la sardana, donat que pot emprar-se com a llibre autodidacte.

Deixant de banda l'ensenyament de la sardana, l'estudi també intenta mostrar diferents aspectes que giren al voltant d'aquesta dansa. Primerament, reconèixer-li el mèrit de ser transmissora d'uns valors culturals i eina d'enllaç amb altres cultures donat que aplega diferents aspectes: per una banda, la música i la coreografia característiques, i per l'altra, l'art i la literatura que ha inspirat. Així mateix, ressaltar la importància de poder escoltar la sonoritat peculiar de la cobla a la plaça i a l'aire lliure, en contraposició a la important divulgació i acceptació que avui dia té la música enregistrada; el valor de veure els músics amb els seus instruments interpretant unes melodies senzilles o altres de més complicades amb dificultats tècniques evidents. També valorar l'ofici de músic de cobla que, des de molts anys enrere, segueix les festes de pobles i ciutats, i la majoria de les vegades sap tocar més d'un instrument perquè és capaç d'interpretar diferents estils de música i adaptarse als horaris proposats pels organitzadors i el públic, compartint a vegades una altra activitat professional.

De la mateixa manera, apunta també l'interès dels constructors d'instruments per obtenir sonoritats acurades que permetin millorar el so del conjunt, la fusió amb altres instruments -violoncel, saxo-i la interpretació a càrrec d'altres agrupacions que no són estrictament la cobla -Companyia Elèctrica Dharma, Santi Arisa \& lakatans, Transardània orquestra. Vol donar a conèixer que la sardana és una dansa viva perquè es pot ballar tot seguint el puntejat establert, i també permet introduir altres punts i variants coreogràfiques.

L'aportació innovadora d'UN TRES / FORA! és la incorporació d'uns gràfics anomenats sardanagrames on s'indiquen els compassos dels dos temes musicals (curts i llargs), el repartiment, el punteig dels dos peus, els salts i aires i l'entrada de la cobla o de l'instrument solista. Permet també fer anotacions sobre qualsevol altre aspecte, com pot ser la inclusió de punts lliures a voluntat dels balladors. Totes les sardanes esmentades al llibre tenen el seu corresponent sardanagrama (Figura 1), de manera que és molt útil el treball de l'audició amb el gràfic prèviament al ball donat que l'alumnat coneix els temes musicals, identifica els diferents timbres, raona el repartiment i pot aportar innovacions amb la incorporació de nous punts -els anomenats punts lliures-, ja siguin de creació pròpia o de colles de balladors.

Es pot pensar que la sardana no té cap interès per als joves d'avui dia, però les experiències que hem dut a terme fins ara aplicant els continguts d'aquest treball indiquen que la dansa, tractada convenientment, pot ser engrescadora i motivadora. La sardana conté elements de llenguatge musical que s'acosten molt a algunes de les preferències de l'alumnat: en primer lloc, està formada per dos temes musicals que es van repetint al llarg de la composició, com la majoria de cançons comercials i, en segon lloc, se sol escoltar en directe, tal com prefereixen sentir la música la majoria de joves, en un punt de trobada.

Com a criteri general, recomanem que l'ensenyant procuri transmetre uns valors culturals i uns coneixements musicals amb il.lusió i amb el repte d'aprendre; ensenyar a escoltar tant les sardanes històriques com les més innovadores; valorar la interpretació musical de la cobla i la importància de sentir-la en directe a la plaça; finalment, conèixer el lligam de la cobla amb la societat catalana i respectar tant la tradició com les innovacions. Només cal afegir que la música és un vehicle de comunicació cultural: el coneixement, l'estimació i el respecte per les pròpies arrels són la base per establir lligams amb altres cultures. Amb aquestes premisses prèvies, l'alumnat de procedència i ètnia diversa pot també desenvolupar correctament l'aprenentatge de la dansa perquè els valors de la sardana es basen en el coneixement cultural i en el respecte de la societat que els ha acollit, que és representada en el sistema escolar.

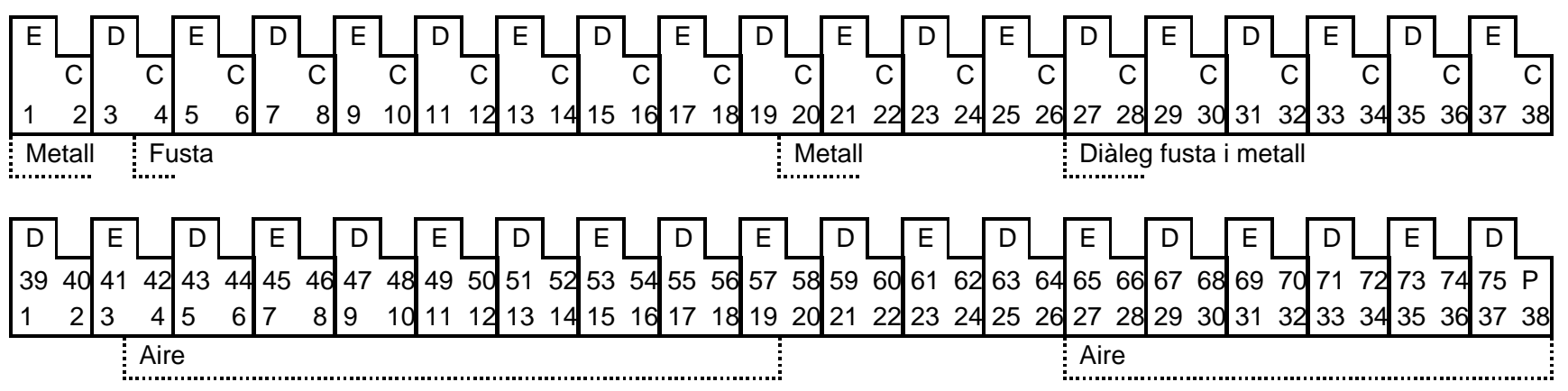

Fig. 1. Sardanagrama de Sant Martí del Canigó, de Pau Casals Defilló 